\title{
VIDA BUENA, VULNERABILIDAD Y EMOCIONES: LA RELEVANCIA ÉTICA DE LOS ACONTECIMIENTOS INCONTROLADOS DESDE LA PERSPECTIVA DE MARTHA NUSSBAUM
}

\author{
Iván Alfonso Pinedo Cantillo* \\ doi: 10.11144/Javeriana.uph36-73.vbve
}

\section{RESUMEN}

La noción de vulnerabilidad es una de las comprensiones teóricas más originales que atraviesa el proyecto filosófico de Martha Nussbaum. Inspirada en Aristóteles y en una relectura de las tragedias griegas, la filósofa norteamericana recupera un aspecto importante para la reflexión ética y política contemporánea: nuestra continua exposición a situaciones inesperadas, mudables o contingentes de la fortuna que pueden afectar considerablemente nuestra búsqueda de la vida buena, y las emociones altruistas como respuesta a esa esencial fragilidad que nos conforma. En este artículo se ofrece una reconstrucción de la idea de agente moral vulnerable como reflexión clave que permite articular en el pensamiento de la autora diversas concepciones sobre justicia social, dignidad humana y calidad de vida, con intuiciones acerca del cultivo y refinamiento de ciertas emociones morales que son relevantes para contrarrestar la frecuente incapacidad para ver al "otro diferente" como alguien plenamente humano.

Palabras clave: Nussbaum; vulnerabilidad; emociones; justicia; compasión

\footnotetext{
Universidad Nacional de Colombia, Bogotá, Colombia. Grupo de investigación Estudios sobre el desarrollo socio-moral.

Correo electrónico: iapinedoc@unal.edu.co.

Para citar este artículo: Pinedo Cantillo, I. A. (2019). Vida buena, vulnerabilidad y emociones: la relevancia ética de los acontecimientos incontrolados desde la perspectiva de Martha Nussbaum. Universitas Philosophica, 36(73), 187-214. ISSN 0120-5323, ISSN en línea 2346-2426. doi: 10.11144/Javeriana.uph36-73.vbve.
} 


\title{
GOOD LIFE, VULNERABILITY AND EMOTIONS: THE ETHICAL RELEVANCE OF UNCONTROLLED EVENTS FROM THE PERSPECTIVE OF MARTHA NUSSBAUM
}

\begin{abstract}
The notion of vulnerability is one of the most original theoretical underpinnings of Martha Nussbaum's philosophical project. Inspired by Aristotle and by a reappraisal of Greek tragedy, the American philosopher recovers an important perspective for contemporary ethical and political reflection: our continuous exposure to unexpected, changing or contingent situations of fortune that can considerably affect our search for a good life, and altruistic emotions as a response to that essential fragility that shapes us. This article offers a reconstruction of the idea of a vulnerable moral agent as a key insight that allows Nussbaum to articulate a more pregnant conception of social justice, human dignity, and quality of life, incorporating intuitions about the nurturing and refinement of certain moral emotions which are relevant to counteract our all too frequent failure to see the "other different" as fully human.
\end{abstract}

Keywords: Nussbaum; vulnerability; emotions; justice; compassion 
La vulnerabilidad es, sin duda, una de las cuestiones centrales de mi obra. En ella se vinculan dos grandes temas de mi trabajo: las emociones y la filosofía política. Las emociones que analizo implican el reconocimiento de nuestra vulnerabilidad ante elementos externos que no controlamos. Siempre que trabajo en filosofía politica me pregunto cómo es posible que la sociedad enfrente la vulnerabilidad humana, cómo es posible hacer desaparecer algunas formas de vulnerabilidad, dar más seguridad, haciendo disponibles para las personas las formas buenas de vulnerabilidad a través del amor, la amistad y otras emociones. Nussbaum (2011, pp. 88-89)

\section{Introducción}

LA EMOCIÓN ha demostrado ser desde la antigüedad un concepto difícil de definir y un término que congrega muy variadas interpretaciones. Desde los primeros filósofos griegos, la emoción ha estado en el centro de las preocupaciones reflexivas e intentos conceptuales que buscan explicar la complejidad del comportamiento humano. Sin embargo, a pesar de la larga historia de este término, la pregunta por las emociones permanece hoy en día abierta a la discusión. Estas se encuentran en el núcleo de quienes somos, pero su naturaleza, estructura, función y rasgos definitorios continúan siendo hoy en día objetos de un amplio campo de investigación para diferentes áreas del conocimiento y nuevas perspectivas de análisis, que buscan esclarecer este fenómeno de la existencia humana.

Después de un largo periodo en donde el tema de las emociones fue abordado casi solitariamente por la filosofía, desde finales del siglo XX y lo que va corriendo del XXI, asistimos a un renovado interés científico en torno a este aspecto tan decisivo del comportamiento humano. Disciplinas como la psicología, la biología y las neurociencias, entre otras, han realizado importantes aportes de cara a la pregunta acerca de qué son las emociones y cómo se expresan, de tal forma que en la actualidad contamos con un amplio debate de ideas en donde se rehabilitan antiguas concepciones filosóficas sobre la naturaleza de las emociones, a la vez que se postulan novedosos enfoques teóricos que enriquecen y redefinen la comprensión de este objeto de estudio.

En este contexto de indagación acerca de la naturaleza de las emociones encontramos el pensamiento de Martha Nussbaum, considerada por muchos 
académicos como una de las filósofas actuales más notables, pues se ha convertido en un referente para todos aquellos interesados en comprender las teorías cognitivas de la emoción y sus posibles relaciones con consideraciones éticas, políticas y educativas. En efecto, el estudio de las emociones ocupa un lugar central dentro del pensamiento filosófico de Nussbaum, pero su interés por entender la naturaleza de las emociones se encuentra estrechamente ligado a su preocupación por generar una visión ética normativa que oriente a las actuales sociedades democráticas, liberales y participativas a defender un modelo de humanidad y de ciudadanía en donde la consideración de aspectos relacionados con la justicia social y la igualdad de oportunidades para todos, el respeto a la dignidad humana y la comprensión de la vulnerabilidad que nos es constitutiva se establezcan como principios rectores de la deliberación moral y política.

Siguiendo una particular concepción terapéutica de la filosofía, esto es, como una práctica que debe traer alivio a los problemas más acuciantes del ser humano, Nussbaum recorre diversas tradiciones de pensamiento que le permiten rehabilitar una perspectiva que, sin duda, se había descuidado en el último siglo: la centralidad de las emociones en la vida moral y las consecuencias prácticas que se derivan de esta reflexión, tanto para la toma de decisiones en la esfera individual como para la deliberación pública.

Para Nussbaum, las emociones se encuentran en estrecha relación con los problemas del bien y del mal, de la felicidad, de la vida en comunidad, de la justicia y del sufrimiento que inevitablemente atraviesa nuestra existencia. Las emociones son los vínculos que conectan al ser humano con lo que está fuera de él; son los lazos que lo unen con las cosas, el mundo, los demás seres vivos y con la misma divinidad. Así se explica que desde la antigüedad se elaboraran sistemas filosófico-morales directamente preocupados por las pasiones, y que consideraron este como un problema de la mayor relevancia para el hombre (Kristjánsson, 2018).

Martha Nussbaum aborda las emociones como un medio para cultivar la justicia, los principios políticos básicos y la ciudadanía democrática que se necesita en las condiciones sociales, políticas y económicas que vivimos actualmente. En este sentido, aspectos que son de gran relevancia para la vida en sociedad, como la preocupación por los otros, la educación de los ciudadanos, el derecho y la cultura política, son, entre otros elementos, realidades humanas que terminan siendo afectadas por el repertorio emocional que nos conforma. De ahí el potencial 
moral que Nussbaum percibe en el cultivo y refinamiento de ciertas emociones, como la compasión, que considera fundamentales para edificar relaciones constructivas con los demás y para instaurar una sociedad justa y decente.

De acuerdo con esta reflexión, podemos decir que la comprensión de las emociones y su relación con la vida moral, la búsqueda de la justicia política y la educación para una ciudadanía democrática constituyen problemas filosóficos centrales alrededor de los cuales se estructura el proyecto filosófico de Nussbaum. Todos estos focos de interés los ha desarrollado la autora sin abandonar su predilección original por el lenguaje y la imaginación literaria, que explora en la mayoría de sus obras. La literatura, como en sus primeros años de investigación, continúa siendo un instrumento privilegiado para fomentar el interés y la reflexión sobre diversos temas éticos, emocionales y educativos, que son relevantes para los hombres y mujeres de hoy (Nussbaum, 2005).

Las tragedias griegas y las novelas contemporáneas, dice la autora, guardan una estrecha relación con la concepción aristotélica de la buena vida y de su fragilidad, pues son fundamentalmente relatos que hablan a los seres humanos de otros seres humanos sometidos a la finitud, las variaciones de la fortuna y las dificultades que entraña la deliberación. Estas historias nos permiten trasladarnos imaginariamente a los contextos de los personajes de una manera tan singular que podemos vernos a nosotros mismos en tales o cuales situaciones de elección, e incluso pueden suscitar emociones de compasión, indignación o amor que son difíciles de lograr por la vía de la lectura de tratados de ética o religión. No es, pues, extraño que Nussbaum, asumiendo una postura que otorga un papel esencial a las obras literarias en la investigación ética, recurra con frecuencia a fragmentos selectos de grandes novelistas para dejar sentada alguna reflexión sobre el razonamiento moral, la vulnerabilidad que nos conforma o el sentido de la vida.

La filósofa norteamericana cimenta su teoría de la justicia (el enfoque de las capacidades) y su comprensión de la naturaleza de las emociones en la noción de vulnerabilidad como elemento constitutivo de la condición humana. Se trata de una idea fundamental, cuyo rendimiento teórico atraviesa buena parte de sus posturas éticas, políticas y educativas, otorgándole un sentido particular a la deliberación práctica. La idea de vulnerabilidad le permite a la autora rehabilitar diversos rasgos de la ética de Aristóteles y la pregunta por la vida buena, a la vez que sustenta su intención filosófica de ofrecer claves para una deliberación moral 
normativa anclada en las emociones. Al respecto, nos dice Jiménez (2016): "el punto central de la reflexión ética de Nussbaum es la vulnerabilidad humana, condición con la que están estrechamente vinculadas las emociones, pues si la vida fuera invulnerable las emociones no tendrían lugar" (p. 45).

De acuerdo con lo anterior, en este artículo se ofrece un análisis del concepto de vulnerabilidad como visión antropológica que da sustento y atraviesa el proyecto filosófico de Martha Nussbaum. Se trata de una comprensión de la condición humana que es relevante para entender los vínculos que podemos establecer entre emociones y vida moral, así como también entre emociones y deliberación pública, de tal forma que, equipados con esta concepción del ser humano, podemos abordar una serie de discusiones que influyen en las comprensiones actuales de la justicia política y la filosofía moral.

\section{Vida buena y vulnerabilidad}

Aristóteles (1985) AFIRMa que vivir bien y actuar bien son lo mismo que la eudaimonía (Ética nicomáquea, 1095a 19-20), pero en esta búsqueda del buen vivir nos descubrimos como seres esencialmente vulnerables o frágiles frente a un sinnúmero de circunstancias exteriores que dificultan o contaminan la actividad buena y la excelencia humana. Son situaciones externas, no en el sentido de que estén por fuera del perímetro corporal de la persona, sino en tanto que se retraen parcial o completamente de su control. Aspiramos, pues, a lo largo de nuestra existencia a alcanzar una forma de vida autosuficiente que nos mantenga a salvo de la fortuna, pero la realidad concreta es todo lo contrario: la condición humana y, por tanto, la búsqueda de una vida buena, están sometidas a la contingencia, lo mudable e inesperado, lo que se escapa a nuestro control racional e incluso a nuestra capacidad de acción (Pinedo \& Yáñez, 2017a) . En este contexto, se entiende por fortuna "lo que no le ocurre al ser humano por su propia intervención activa, sino lo que simplemente le sucede, en oposición a lo que hace" (Nussbaum, 1995, p. 31). Esta situación existencial de estar a la deriva de la fortuna es lo que hace vulnerable la vida humana buena y, por consiguiente, sus posibilidades de desarrollo.

Los antiguos griegos ya se habían preguntado por la forma de alcanzar la excelencia humana, y en estas reflexiones se toparon con el problema que representaba 
la fortuna y todo el cúmulo de situaciones que hacían visible la vulnerabilidad de los seres humanos y la contingencia de la vida moral. Aristóteles afirmaba que la felicidad o eudaimonía, más que un estado, es una praxis, pues es según sus acciones y elecciones como viven bien los seres humanos, es decir, se hacen $\mathrm{eu}$ daimones, o lo contrario. Las tragedias reflejan, entonces, esta búsqueda del buen vivir y los obstáculos que pueden aparecer en cualquier momento frente a la vida buena: lo contingente -en griego deinón-, lo que de manera sorpresiva e incontrolada puede acaecer en nuestras vidas y ante lo que hemos de enfrentarnos con prudencia si no queremos crear más dolor o injusticia es una condición a la que siempre estamos expuestos los seres humanos en nuestra búsqueda de la plenitud o vida lograda (Colmenarejo, 2017). Y este es justamente el tema central de $\mathrm{La}$ fragilidad del bien, obra en la que Nussbaum (1995) analiza cómo la vida moral está sometida a circunstancias incontroladas que amenazan el desarrollo de la actividad excelente y nos enfrentan a dilemas en donde el curso de acción nos puede apartar de la plena eudaimonía, o vida buena.

Las tragedias griegas, con sus conflictos prácticos, dan cuenta de esta condición. Los personajes de estas narraciones terminan siendo responsables de sucesos inesperados, que afectan considerablemente su forma de vida. Agamenón, Eteocles, Antígona y Creonte son seres paradigmáticos en la literatura antigua que reflejan la fuerza de los acontecimientos incontrolados en la vida de las personas y nos enfrentan finalmente al mensaje contundente de que la vulnerabilidad es común a todos los seres humanos (Nussbaum, 1995).

Las representaciones teatrales antiguas nos muestran cómo una vida normal se encuentra rodeada de peligros que amenazan su desarrollo ${ }^{1}$. Las tramas de estas narraciones expresan bastante bien cómo la fortuna trae circunstancias

1 La Antígona de Sófocles, una de las tragedias analizadas por Nussbaum, muestra cómo la prudencia es el elemento más importante del buen vivir o eudaimonía. Tras la muerte de Edipo, Eteocles y Polinices, hermanos de Antígona, se disputan el trono de Tebas, hasta el punto de provocar una guerra que culmina con la muerte de ambos. Creonte se convierte en el nuevo rey de la ciudad, ordenando honrar la memoria de Eteocles mientras prohíbe dar sepultura a Polinices, al que considera un traidor por haber provocado una guerra contra su propia ciudad. Antígona considera que es su deber dar sepultura digna a su hermano, aunque ello le lleve a una muerte segura. Creonte es inflexible en su condena: no perdona a Polinices, ni ahora a Antígona. Su decisión provoca una serie de muertes en cadena: la de Antígona, la de su propio hijo, prometido de Antígona, y la de su propia esposa quien no puede soportar la muerte de su hijo. La prudencia enseña que pretender 
que privan, limitan o entorpecen la búsqueda de la excelencia humana, y que también afectan el carácter de la persona, o las fuentes internas de la acción, conduciendo a una pregunta de fondo: ¿cómo se puede decir que vive bien un individuo sometido a la desdicha, al ultraje, la tortura, el hambre, las penurias y la discriminación? (Bieda, 2008).

Esta continua exposición a situaciones dominadas por la fortuna lleva a Nussbaum a defender que el agente moral es un ser frágil, expuesto al sufrimiento inmerecido, sometido a la inseguridad, y cuyo florecimiento puede ser dañado gravemente si su dignidad no es reconocida por los otros. Esta concepción literaria conduce, entonces, a sustentar la tesis según la cual los acontecimientos que están más allá del control del agente son verdaderamente importantes para la cualidad ética de la vida:

Los vínculos con nuestros hijos, padres, seres queridos, conciudadanos, nuestro país, nuestro propio cuerpo y nuestra salud son el material sobre el cual trabajan las emociones, y estos lazos, dado el poder del azar para destruirlos, vuelven vulnerable la vida humana (Nussbaum, 1997, p. 89).

La vulnerabilidad es un concepto que recoge diversas características de la condición humana, lábil y necesitada, y en palabras de Nussbaum las emociones "son respuestas a las áreas de vulnerabilidad, en las que registramos los perjuicios que sufrimos, que podríamos sufrir, o que por suerte no padecemos" (Nussbaum, 2006, p. 16). La contingencia -el azar, la fortuna, lo que nos sucede sin querer, lo que puede pasar- es una experiencia fundamental que todos los seres humanos vivimos en un momento u otro de nuestras vidas; es una condición que pone al descubierto cómo la construcción cotidiana de una buena vida es una tarea compleja marcada por avatares de todo tipo que amenazan continuamente este fin, obstaculizando también nuestra capacidad de decidir y actuar. Si los infortunios llegan a ser graves y se prolongan en el tiempo, cualquier agente moral podría verse apartado seriamente de la eudaimonía.

En este sentido, la consideración de la fragilidad de la vida buena se convierte en un punto de apoyo muy importante para el pensamiento de Nussbaum,

mantener una norma humana contraviniendo una norma divina genera más daño y dolor que la renuncia a esa norma humana, generalmente sustentada en la soberbia (Colmenarejo, 2017, p. 41). 
pues a partir de esta reflexión puede preguntarse por qué y hasta qué punto la eudaimonía necesita de los bienes exteriores, aspecto que influye en la manera de comprender la justicia social como una fundamentación y defensa de aquellos recursos básicos que las personas necesitan para su florecimiento y para vivir en unas condiciones de dignidad auténticamente humana (Abbate, 2017).

La fragilidad de la vida nos vuelve necesitados no solamente de bienes exteriores como la riqueza, la vivienda y el poder político, sino de vínculos humanos que Aristóteles analiza bajo la categoría de philia, habitualmente traducida por amistad: es una categoría amplia que incluye los vínculos por parentesco, compañerismo, asociación, amor filial y, por último, los lazos que se pueden denominar civiles y políticos pues, como dice el filósofo, los hombres no podían bastarse a sí mismos en el aislamiento (Lacunza, 2015). En estas relaciones se encuentra el principio y el origen del amor, del Estado y de la justicia, porque solo otro ser humano puede reconocer nuestra humanidad y hacerse cargo de nuestras debilidades.

Los dioses, por el contrario, no están expuestos a esta condición, porque son invulnerables al sufrimiento y totalmente autosuficientes; tales seres no tendrían ningún motivo para temer, porque nada que pudiera sucederles sería realmente malo. Una forma de existencia así es justamente la que plantean los estoicos al proponer un modo de ser casi invulnerable a las vicisitudes de esta vida, una forma de anulación de los vínculos con este mundo, en donde hay alegría y también mucho dolor (Pinedo \& Yáñez, 2017a, p. 58).

Los estoicos desconfiaban de las emociones porque nos hacen ver como personas cuyo bien depende de cosas externas a la virtud y a nuestro pensamiento; al estar sometidos a cosas inestables, poco fiables, vivimos dando importancia a los llamados "bienes de relación", los lazos familiares, el país de pertenencia, la salud, el cuerpo (Abbate, 2017). Para el estoico, por tanto, la felicidad se encuentra en la libertad del hombre que no se liga más que a lo que depende de él, a lo que cae bajo el imperio de su voluntad, de suerte que, frente a todo lo demás -contingencias materiales, opinión de los otros, buena o mala fortuna- practica la más perfecta indiferencia (Knuuttila, 2004). Con estos argumentos, los estoicos proponían la búsqueda de la purificación de las emociones, una postura que, sin embargo, puede conducir fácilmente a la indiferencia, a la desconsideración y 
a una forma de deshumanización, al no reconocer la fragilidad constitutiva de la existencia humana. Nussbaum, siguiendo a Aristóteles, considera en cambio que los bienes de relación son fundamentales en la constitución de la experiencia humana, y que su vulnerabilidad, el estar sujetos a la suerte, descubre el lado positivo de la fragilidad humana y de la contingencia (Nussbaum, 2003).

La vida de los reyes y poderosos, tanto en la antigüedad como en la actualidad, da cuenta de un tipo de desconocimiento de lo humano que puede conducir al daño social, al generar sensaciones de invulnerabilidad por el poder del dinero, los lujos y las comodidades. Situados desde una condición de superioridad frente al que sufre y demanda compasión, los poderosos "pasan por alto el carácter meramente coyuntural de su situación o, lo que es lo mismo, olvidan la fragilidad esencial que ambos comparten" (Arteta, 1996, p. 217).

Rousseau ya advertía esta situación al plantear lo fácil que resulta suponer que, en realidad, las personas que no se nos parecen, o vienen de culturas distintas, no sufren tanto como sufrimos nosotros, o que en realidad no sienten su dolor. Según esto, bajo las ideas de invulnerabilidad se pueden cometer los peores desmanes, al no reconocer un rostro humano en el que nos rodea o, lo que es lo mismo, al no reconocer idéntica dignidad a otros seres que, al igual que yo, estamos destinados al dolor y a la muerte. Por eso durante mucho tiempo los reyes se movieron bajo la premisa de superioridad que los hacía pensar en no ser contados nunca como seres típicamente humanos, es decir, en estar segregados de todo ese cúmulo de debilidad, dolor y lágrimas que constituye la condición humana (Nussbaum, 2006).

Pero la realidad es que todos somos individuos frágiles, necesitados e incompletos, expuestos a la enfermedad, al mal físico, al sufrimiento y a la muerte. Además, estamos desvalidos frente a la posibilidad de ser víctimas del mal moral ocasionado por otros individuos, de ser sometidos a tratos inhumanos, humillantes, violentos y degradantes: tenemos una misma vulnerabilidad y mortalidad, esa es la común dignidad que faculta al compasivo a su movimiento peculiar de ponerse en el lugar del otro. Al respecto, la Ética de la compasión de Melich (2010) nos recuerda:

Lo que nos convierte en humanos no es la fidelidad o la obediencia a unas normas, a un código universal y absoluto, sino el reconocimiento de la radical fragilidad y vulnerabilidad de nuestra condición, el hecho de que no podemos 
eludir el tener que responder ante el lamento de aquel otro doliente que me encara y me apela, y de que aunque no le responda, ese "no responder" es ya una forma de respuesta, la indiferencia (p. 237).

Toda concepción de la vida buena que juzguemos lo bastante fecunda para hacerla nuestra contiene ese elemento del riesgo que rodea nuestra existencia. Los daños que nos amenazan, por sernos comunes, nos equiparan y nos ponen en parecida dependencia unos de otros. Este es el primer factor que nos hace iguales como humanos. Hacernos vulnerables ante el otro implica el reconocimiento de la afinidad en la vulnerabilidad de lo humano, y es un reconocimiento imprescindible para llegar a sentir compasión por otra persona o incluso por otro animal no humano, una de las extensiones de la compasión a la que Nussbaum siempre alude en sus obras. Siendo esto así, las emociones de compasión, pesar, temor e indignación son recordatorios esenciales y valiosos de nuestra condición común de humanidad y, por lo mismo, son señales que indican cuándo hay sufrimiento a nuestro alrededor y cuándo la dignidad humana ha sido menoscabada por la acción de otras personas (Colmenarejo, 2017; Pinedo \& Yáñez, 2017a).

\section{Las emociones como respuesta a la condición de vulnerabilidad}

PARA CONTRARRESTAR LA RADICAL VULNERABILIDAD que nos conforma, Nussbaum propone, entre otras emociones morales, la compasión, como el prototipo de sentimientos que merecen ser cultivados en las actuales sociedades democráticas para hacer viables las condiciones de vida digna y justicia social que todos merecemos. Por compasión se entiende una emoción dolorosa orientada hacia el sufrimiento grave de otra persona. Supone una sensibilidad hacia los otros seres humanos que padecen un dolor inmerecido a causa de nuestra común vulnerabilidad, que revela los límites de nuestra autosuficiencia frente a las circunstancias particulares de la vida, y que nos pone de cara a otro ser humano para encontrar alivio o salida. En ese sentido, nos dice la filósofa de Chicago, la compasión puede ser una forma inestimable de acrecentar nuestra conciencia ética y de comprender el significado humano de determinados acontecimientos y políticas. Una sociedad que quiera fomentar el trato justo a todos sus miembros, nos dice, "siempre tendrá razones más sólidas para alentar el ejercicio de la imaginación compasiva que atraviesa las fronteras sociales y propende por la 
defensa de los derechos fundamentales" (Nussbaum, 2001, p. 130). Es, pues, una emoción que nos recuerda que todos nacemos desnudos y pobres, que estamos sujetos a enfermedades y sufrimientos de diversa índole y, por último, que todos estamos condenados a morir. Por tanto, la visión de estos sufrimientos comunes puede llevar la humanidad a nuestros corazones, de tal manera que podamos reconocer que todo ser humano es auténticamente humano y que su valor moral es igual al de cualquier otro.

Según este enfoque, la compasión requiere de sujetos aptos para empatizar con los demás seres humanos, comprendiendo que ese otro, diferente en color, religión, cultura, puedo ser yo mismo en forma real o hipotética, de tal forma que puedo imaginar su situación hasta centrar mi mirada en la condición humana degradada o en el sufrimiento.

El proyecto de Martha Nussbaum en torno a las emociones se encuentra en estrecha relación con su preocupación por reflexionar acerca de una teoría política que tienda hacia la equidad y la justicia social, asumiendo nuestra condición humana marcadamente vulnerable y menesterosa. En El cultivo de la humanidad (2001), El ocultamiento de lo humano (2006), Paisajes del pensamiento (2008), Crear capacidades (2012) y, más recientemente, en Emociones políticas (2014), Nussbaum deja planteado un importante asunto en torno al cual gira buena parte de su reflexión filosófica: el valor ético de las emociones y su influencia en la vida política de las actuales sociedades democráticas. Más precisamente, Nussbaum considera que ciertas emociones públicas están llamadas a apoyar los principios y los proyectos políticos de una sociedad decente, idea que la autora desarrolla a partir de una lectura del liberalismo político propuesto por Rawls (1979) en su noción de una sociedad bien ordenada y estable, que busca la justicia y promueve la ciudadanía democrática. Nussbaum, por tanto, considera que el liberalismo político se puede enriquecer al incluir las emociones como factores que contribuyen significativamente a la necesidad que señala Rawls de otorgar estabilidad a las instituciones básicas de la sociedad, definidas a partir de los principios de justicia que emanan en el contexto de la denominada "posición original”2.

2 La posición original es una situación hipotética desarrollada por Rawls para establecer los principios de justicia que deben orientar a las sociedades democráticas. En este experimento mental, los sujetos habrán de reunirse en una situación imaginaria, como lo habían postulado los primeros 
Desde finales de los años noventa, Nussbaum ha propuesto la idea de que existe un vínculo entre emociones, justicia social y vida moral, que se debe aclarar mediante la elaboración de lo que sería una "psicología política": una explicación de las emociones y de otras disposiciones psicológicas que actúan como apoyos o impedimentos a la realización de un programa de justicia social como el que propone en su teoría de las capacidades humanas. Parte de esta tarea consiste, precisamente, en comprender bien las emociones que sirven de sostén al "enfoque de las capacidades", como la compasión y el amor, que tienen una relevante fuerza motivadora. También aquellas que obstaculizan las conquistas de la justicia, como las diversas formas de asco, vergüenza y odio hacia personas y grupos, lo cual es un combustible que aviva la exclusión de miles de seres humanos y, por ende, de sus posibilidades de florecimiento (Nussbaum, 2008).

La compasión puede servir de sostén a la idea de justicia formulada en el enfoque de las capacidades (Nussbaum, 2002). Sin embargo, esta emoción no es intrínsecamente fiable, teniendo en cuenta que las personas suelen sentirla de un modo restringido y desigual. Por consiguiente, nos dice la autora, dos de las preguntas que se nos plantean frente a las emociones que resultan relevantes para el ámbito de la política son las de

cómo hacer que funcionen como apoyo real para unas políticas basadas en el concepto de la igualdad humana sin despojarlas de su fuerza motivadora, y cómo educar tales emociones sin socavar valores inestimables como los de la libertad de expresión y el debate (Nussbaum, 2012, p. 213).

Nussbaum considera que para llevar a buen puerto esta tarea, debemos aprender todo lo posible acerca de los estudios científicos y experimentales sobre la emoción, ya que estos nos proporcionan puntos de observación y perspectivas

teóricos del contrato social, para establecer normas de justicia de las cuales se beneficien todos. Tales sujetos tienen como característica el ser iguales, libres (autónomos), no determinados por nada, y con capacidad de reclamar beneficios de la cooperación social. Ellos habrán de negociar algunos principios que aseguren las mejores condiciones para sí mismos. Pero, al contrario de esa situación referida en los primeros teóricos del contrato social a imaginados estados de naturaleza en donde los sujetos conocían sus condiciones sociales y sus talentos particulares, en la situación propuesta por Rawls los sujetos que van a postular los principios del contrato no saben cuáles son sus creencias, su situación social, su género, su raza, sus orientaciones políticas, o religiosas, ni aquellas características que los diferencian en el mundo real. 
razonables sobre la estructura de estos fenómenos complejos de la experiencia humana. Paisajes del pensamiento es la obra en que la autora aborda con mayor precisión esta dimensión de su proyecto filosófico. Se trata de una teorización sobre las emociones y sus diversos elementos constitutivos a partir de una recuperación de nociones estoicas, así como de diversos trabajos experimentales en psicología, biología y neurociencias. Como en otros textos, la literatura ocupa un lugar destacado como instrumento apropiado para captar la profundidad de estas experiencias humanas y como elemento didáctico que ofrece algunas orientaciones para lo que sería un programa de educación y refinamiento de las emociones políticas. La filósofa llega, entonces, al tratamiento de las emociones y su relación con el razonamiento ético como un medio para cultivar la ciudadanía democrática que se necesita en las actuales sociedades liberales (Nussbaum, 2008; 2012).

\section{El valor de las emociones públicas en la convivencia civil y democrática}

Como parte de la Cimentación de su proyecto, Nussbaum ofrece una crítica del liberalismo de Rawls, que busca responder a la pregunta sobre cómo es posible que exista una sociedad justa y estable de ciudadanos libres e iguales, pues considera que la teoría de la justicia rawlsiana excluye la vulnerabilidad humana y el repertorio emocional que nos conforma, aspectos que son decisivos en el cultivo de virtudes morales, cívicas y políticas que permiten asegurar a los ciudadanos los principios de justicia previamente establecidos. Esto se traduce en que no basta con fundar en principios racionales la realización de la libertad y la igualdad, sino que la cooperación entre ciudadanos libres e iguales está mediada por las emociones como dimensiones de nuestra naturaleza, que impulsan a la acción y hacen efectivos los valores de dignidad, respeto y equidad que estructuran la justicia social.

En Liberalismo político, Rawls (1995) centra la concepción política de la persona en la libertad y la igualdad, y refiere dos poderes de la personalidad moral que caracterizan a los seres humanos: la capacidad de desarrollar un sentido de la justicia y la capacidad de construir una concepción del bien. Sin embargo, esta concepción racionalista de los seres humanos no tiene en cuenta las emociones como fenómenos que pueden afectar considerablemente la agencia humana, y que se expresan e influyen en la vida social y política. 
Si bien Rawls no cierra la puerta a considerar algunos aspectos de psicología moral que pueden ser importantes dentro de su concepción política, evita comprometerse con temas complejos, como las emociones, que pueden afectar el punto de partida del consenso superpuesto. A lo sumo, otorga a ciertos sentimientos morales, como la indignación y el resentimiento, un papel importante en relación con el sentido de justicia. En su texto, nos dice Rawls (1995), refiriéndose a los bienes primarios como necesidades de los ciudadanos: "los sentimientos fuertes y las aspiraciones muy profundas hacia ciertas metas no pueden, como tales, motivar que la gente reclame la asignación de recursos sociales, ni para exigir a las instituciones públicas que asignen recursos para lograr esos fines" (p. 185).

Rawls, preocupado por recuperar el aliento ético-político de la razón clásica ilustrada, precisamente deja las emociones, devociones y afectos fuera de los principios de justicia, y en su lugar postula un matizado desdoblamiento del concepto de razón en racionalidad (que abarca la autonomía moral y la procura de los propios intereses) y razonabilidad (la capacidad para llegar a acuerdos cooperativos para fundamentar las instituciones democráticas). Junto a esto, su tesis de la prioridad de la justicia sobre el bien y su noción de que las ideas del bien no pertenecen a la razón pública, sino que corresponden propiamente a usos no públicos de la razón que deben permanecer en el ámbito de la privacidad, se traduce en la exclusión de las convicciones y pasiones de la mayoría, así como los vínculos y las lealtades del ámbito de la política (Máiz, 2010).

En estas fisuras del liberalismo de Rawls, Nussbaum encuentra un lugar para su propuesta, que concede enorme importancia a las emociones en la deliberación pública. Lejos de la idea de que las emociones son ciegas e irracionales, su teoría cognitivo-evaluativa se establece como sustento de la cultura pública y como un apoyo para que las sociedades democráticas liberales actuales puedan aspirar a un renovado ideal de justicia social. Para tal efecto, manteniendo el trasfondo de la teoría de la justicia como imparcialidad, Nussbaum (2014) sostiene que las naciones cimentadas en el liberalismo están comprometidas con el cultivo de ciertas emociones políticas que ayudan a sostener sus más preciados objetivos: "todo ideal político está sustentado por sus propias emociones características” (p. 143).

Las emociones, con su contenido intencional, son el sustento de los principios y los valores políticos, ya que la materialización y el sostenimiento de los mismos solo es viable en la medida en que cuentan con un compromiso social, 
con una motivación de los ciudadanos que les procure estabilidad a lo largo del tiempo. La mera y fría devoción del ciudadano a sus deberes políticos, en cuanto deberes, no parece ser el principal motivo que genera compromisos con los demás, sino que es necesario apelar a nuestra textura emocional para reconocer en el otro su plena humanidad. Las emociones públicas pueden constituir elementos fundamentales de una aspiración a la justicia, y pueden funcionar realmente sin eliminar la libertad liberal, e incluso potenciándola:

mi enfoque necesita recurrir al altruismo y, por consiguiente, está obligado a explicar detalladamente cómo y por qué surgen las motivaciones altruistas, con qué otras motivaciones deben competir y cómo podríamos cultivar los sentimientos útiles de un modo socialmente propicio [...]. Hoy tenemos la urgente necesidad de contar con una buena teoría explicativa de las emociones de los ciudadanos y las ciudadanas en una sociedad digna. Esta tarea exige una reflexión conceptual sobre las emociones, sobre cómo surgen y se despliegan, sobre cuál es su estructura y sobre cómo interactúan entre sí (Nussbaum, 2012, p. 120).

En La terapia del deseo ya Nussbaum (2003) anunciaba esta recuperación de las emociones a partir de una revisión crítica de Aristóteles, los estoicos y los epicúreos, de tal forma que paulatinamente aproxima estas reflexiones antiguas a problemas actuales mediante una concepción normativa que comprende a las emociones como parte indispensable de la vida humana buena, la acción virtuosa y la deliberación política.

En el amplio comentario que hace Nussbaum de La religión del hombre (Tagore, 1963), en su libro Emociones politicas para ejemplificar algunos aspectos de su teoría, nos dice la filósofa que el poeta bengalí ya prefiguraba una imagen de la evolución hacia el respeto interreligioso y la afirmación de ciertos principios compartidos que humanizan la realidad en el seno de sociedades que aspiran a la justicia, y en donde seguramente siempre estarán vigentes la diversidad religiosa y los proyectos de vida de cada individuo. En la escuela que Tagore fundó en Santinikentan (India), los estudiantes podían cultivar emociones de compasión y simpatía extendidas anulando las viejas prácticas de intocabilidadad y asco, la expresión visible de la jerarquía de castas (Nussbaum, 2014). 
Gandhi también captó desde muy temprano ese mundo de asco y segregación propio de la India, y por eso siempre procuró tener gestos emocionales de inclusión, amor y generosidad hacia todos. El cuerpo mismo de Gandhi era una imagen de la justicia que se debía implantar en un mundo marcado por la segregación y la pobreza, por lo que fue protagonista de ingeniosas representaciones dramáticas que invitaban a una construcción nacional distinta, fundamentada en la promoción del bienestar común. Tagore, Gandhi y Nehru pensaron largo y tendido desde su contexto en cómo podrían contribuir los políticos a construir una cultura pública que pusiera el acento en el altruismo y la atenuación del sufrimiento; eran, por tanto, ideas que prefiguraban una nueva India, en donde se cultivaran emociones positivas cuyo centro era el ser humano y su condición vulnerable (Nussbaum, 2014).

Siguiendo estas reflexiones, Nussbaum considera que su proyecto, que da relevancia a emociones públicas como la compasión y el amor en la consecución de la justicia social, resulta coherente para lo que denomina sociedades democráticas reales que, aunque imperfectas, aspiran a la justicia y a la maximización de las capacidades humanas; es decir, en sociedades que, a pesar de las limitaciones propias de nuestra naturaleza, se orientan por principios de justicia, igualdad y dignidad humanas, buscando garantizar que todos tengan el derecho a habitar el mundo con libertad, sin exclusión y sin estar expuestos a sufrimientos o penurias que son políticamente evitables (Nussbaum, 2007; 2014).

No basta, entonces, con el procedimiento abstracto del consenso superpuesto planteado por Rawls para hacer posible la justicia como imparcialidad, sino que una sociedad atenta a la libertad e igualdad humanas debe nutrirse de la labor de las instituciones y de las actitudes de los ciudadanos. ¿Qué hace que la gente se considere responsable de los demás o sienta que tiene unos deberes de respeto mutuo hacia personas que no hacen parte de su círculo más inmediato? Para dar respuesta a este interrogante, Nussbaum considera que es importante tener ciudadanos cuya imaginación y emociones sean sensibles a la situación de la nación, a la de sus conciudadanos y al reconocimiento del dolor y la vulnerabilidad humana en cualquier lugar del planeta donde acontezca. Es precisamente esta sensibilidad la que permite apreciar cómo la democracia se fractura con la alienación que producen las profundas desigualdades y el sentimiento de abandono e indiferencia que fácilmente surge entre las minorías marginadas (Modzelewski, 2017). 
El sujeto "descarnado" que propone Rawls en su concepción de la posición original, sin vínculos emocionales, sin lazos comunitarios, que opera sin ninguna característica que le permita identificarse como sujeto (aspecto que retoma de los planteamientos de Kant) es el foco adonde se dirigen diversas críticas realizadas a las éticas deontológicas, y al liberalismo, en tanto no permiten reconocer los motivos afectivos y personales que llevan a los seres humanos a comportarse moralmente.

Las críticas comunitaristas de Sandel, MacIntyre y de los autores provenientes del republicanismo contemporáneo (Pettit, 1997), ya ponían de presente desde hace varios años estos límites del liberalismo de Rawls, que descuidaba sustancialmente la importancia de los vínculos humanos en la construcción de la justicia. Para Sandel (2000), la teoría de la justicia requiere de una concepción de comunidad para ser coherente. La comunidad define los límites del yo, que no coinciden necesariamente con los límites corporales de los individuos. Los nuevos límites del yo, desde la perspectiva comunitarista, se establecen a partir de la constitución de la identidad personal. Esta configuración de la identidad personal procede de aquellos atributos que permiten al individuo ser quien es, pero estos atributos no son propiedad del individuo. Por el contrario, la comunidad es el sujeto de la posesión de los atributos que permiten la constitución de la identidad personal.

Para MacIntyre (1987), el agente moral adquiere su capacidad como tal en el contexto de una sociedad en particular, y ningún individuo se siente verdaderamente ligado a una moral abstracta o impersonal; en otras palabras, sin comunidad de lealtades, afectos y devociones no hay agente moral. Más allá de la autonomía personal, es necesario reconocer la pertenencia y la identificación del individuo con una comunidad determinada que forma lo que el sujeto es y puede ser como agente moral. Todos nosotros nos relacionamos con nuestras circunstancias en tanto que portadores de una identidad social concreta. Soy hijo o hija de alguien, ciudadano de esta o aquella ciudad, pertenezco a este clan, tribu o nación. Por tanto, lo que sea bueno para mí, debe ser bueno para quien comparta esas redes sociales.

Como tal heredo del pasado de mi familia, mi ciudad, mi tribu, mi nación, una variedad de deberes, herencias, expectativas correctas y obligaciones. Ellas constituyen los datos previos de mi vida, mi punto de partida moral. 
Confieren en parte a mi vida su propia particularidad moral (MacIntyre, 1987, p. 271).

Así, pues, las discusiones comunitaristas y republicanas ponen de relieve diversas falencias del liberalismo de Rawls, y aunque en este espacio no se pretende hacer una revisión de estas posturas, se subraya cómo estas corrientes de pensamiento empiezan a proponer diversas aproximaciones teóricas que reclaman un vínculo entre concepciones de la justicia y nuestra constitución emocional capaz de hacer viables los distintos idearios que abogan por una distribución equitativa y por el respeto de la esencial dignidad de todos.

De acuerdo con esto, la primacía de la justicia en la estructura básica de la sociedad, tal y como propone Rawls, alcanzaría un sentido más completo al introducir diversos sentimientos fraternales y de benevolencia que le brinden estabilidad a lo largo del tiempo. Las emociones tienen un lugar determinante en la racionalidad práctica, al ser advertidoras del daño moral, la vulnerabilidad y el menoscabo de la dignidad humana, de tal forma que, al percibir la fragilidad de nuestra condición, proveen una serie de motivos para actuar. Incluso los sistemas legales deben otorgar un rol normativo sustancial a algunas emociones y a algunas normas de razonabilidad referentes a ellas; este es un tema ampliamente desarrollado por Nussbaum (2006) en El ocultamiento de lo bumano.

La vida pública es, pues, el dominio en que se despliegan nuestras emociones, contribuyendo a que el sentido de la justicia se concrete en las estructuras básicas de la sociedad y en acciones ciudadanas de preocupación por la suerte de los demás (Gil, 2014). Y eso no es algo completamente nuevo: nos dice Nussbaum que en la antigua Grecia la vida humana buena era una vida con y hacia los otros, y por eso todas las virtudes y emociones tenían una dimensión social. Los hombres atenienses no reservaban la expresión del amor, el sufrimiento y la ira para el ámbito privado del hogar. La esfera pública estaba teñida de la energía emocional e imaginativa que, en cambio, solemos asociar hoy en día más bien con la esfera privada (Nussbaum, 2005).

En Paisajes del pensamiento: la inteligencia de las emociones, Nussbaum (2008) expone en detalle su visión cognitivo-evaluadora de las mismas, la cual es el resultado de una relectura de los planteamientos estoicos sobre las emociones, entendidas como juicios de valor, en combinación con una recuperación del concepto de eudaimonía propio de la tradición aristotélica. En el pensamiento 
de Nussbaum, los juicios valorativos juegan un rol esencial para que se produzca la reacción emocional, y es a través de ellos como podemos encontrar una conexión entre emociones y vida moral. Los juicios son propiedades de lo emocional que podemos rastrear en diversos textos antiguos, pero que se han recuperado de manera más explícita y con mayor elaboración conceptual en la psicología y filosofía contemporánea de las emociones que se viene desarrollando desde finales del siglo pasado, cuando se dio el giro de las teorías fisiológicas a las teorías cognitivas de la emoción (Pinedo \& Yáñez, 2017a).

El pensamiento de Nussbaum, fundamentalmente, implica una reconceptualización en torno al origen, estructura y cultivo de las emociones, tradicionalmente interpretadas en la filosofía occidental como impulsos o fuerzas irracionales descontroladas que son un obstáculo para la determinación de la conducta moral. A pesar de existir desde tiempos antiguos posturas que abogaban por integrar las emociones y la razón, y por incorporar estas expresiones en el comportamiento moral, las posturas que han dominado en nuestra historia occidental han sido las que defienden las dicotomías y oposiciones entre estos dos conceptos (Cabezas, 2014; Pinedo \& Yáñez, 2017b). Sin embargo, esta perspectiva dicotómica, en la actualidad, tiende a su disolución con el surgimiento de nuevos planteamientos, como los de Nussbaum, que establecen una interdependencia entre cognición y emociones, y una relación estrecha entre emociones y vida moral.

Inspirada en Aristóteles y en el estoicismo antiguo, Nussbaum concibe una teoría cognitivo-evaluadora de las emociones que las entiende como un tipo especial de juicios: juicios de valor o evaluaciones que permiten ver el mundo desde el punto de vista de nuestro esquema de objetivos y proyectos: las cosas a las que asignamos valor en el marco de una concepción de lo que para nosotros significa el florecimiento de una vida humana buena (Nussbaum, 2006; 2008; 2014). Si bien su teoría no aborda todos los tipos de emoción, en Paisajes del pensamiento (2008) expone una amplia interpretación de la dimensión cognitiva de la compasión, considerada positivamente por la reflexión filosófica como una emoción que ofrece un buen fundamento para las acciones adecuadas desde el punto de vista moral.

Para nuestra autora, la compasión es un sentimiento que va asociado directamente con la justicia y ocupa un lugar central en sus propósitos educativos y 
en su ideal de construir una nueva cultura política pública. Con la compasión se garantiza que los sujetos se apropien del sufrimiento ajeno mediante una genuina unificación afectiva, lo que hace que sea una emoción moral fundamental o la emoción social básica, tal y como la misma autora reconoce (Nussbaum, 1996). Por tanto, es una emoción que requiere un conjunto complejo de conceptos relacionados con los valores morales, una conciencia de las distinciones morales, de lo correcto o incorrecto, justo o injusto, y una capacidad adaptativa para interpretar correctamente el estado mental de alguien que puede influir en nuestro bienestar.

La compasión es una emoción que posee un potencial relevante para la reflexión ética, porque va asociada a la deliberación humana de cómo vivir bien y cómo alcanzar una vida plena o consumada, reconociendo la fragilidad y la reciprocidad en las relaciones humanas. Es una intuición moral que nos informa acerca del mejor modo de comportarse para contrarrestar, mediante la consideración, el respeto y la benevolencia, la extrema vulnerabilidad de las personas, de tal forma que puede ser vista como un mecanismo protector o compensador de esa fragilidad esencial que nos es constitutiva y que se manifiesta en las distintas formas de sufrimiento que limitan nuestro florecimiento (Pinedo, 2018; Seppala, Simon-Thomas, Brown \& Worline, 2017). También es una emoción vinculada con la búsqueda de la justicia y la acción moral, en donde se pone en juego la conciencia por medio de juicios, decisiones y compromisos que dan cuenta de los principios y fines que orientan a la persona, y que son capaces de humanizar la realidad al traducirse en obras para los demás. Por esta razón la compasión en el pensamiento de Nussbaum $(1996 ; 2008)$ puede tener un rol importante dentro de una teoría ética normativa que tenga en cuenta las emociones como elementos centrales que ayudan a advertir sobre la presencia de daños morales y sufrimiento, obstáculos para el desarrollo de una vida humana buena.

Este compadecerse del sufrimiento ajeno, nos dice Nussbaum, cuanto más puro y genuino sea, debe trascender la esfera de la vida privada para tocar aspectos fundamentales de la vida pública de los ciudadanos. De ahí que la filósofa considere la compasión como la emoción moral por excelencia que se necesita en las actuales democracias liberales para cultivar y ensanchar el interés por los demás, para defender la igual dignidad y valor de todos los seres humanos, y para hacer frente al sufrimiento en todas sus formas, sin importar que la experiencia 
de dolor acontezca en vidas distantes y distintas al entorno más inmediato en que nos encontramos (Nussbaum, 2014). Panea (2018), complementa esta reflexión diciendo:

La imaginación compasiva puede jugar un importante papel a la hora de determinar las necesidades humanas de los bienes primarios, y en la elección de los principios distributivos más elementales de la rawlsiana "posición original”. Pero también puede irse plasmando en la legislación concreta, a medida que se detallen cuestiones relativas al bienestar, a la desigualdad humana, o si nos preguntamos sobre los deberes de las naciones más ricas sobre las más pobres (p. 120).

Las emociones públicas son, por consiguiente, fuente tanto de estabilidad para los principios políticos positivos, como de motivación para hacerlos efectivos: los valores políticos centrales, como la igualdad racial, por ejemplo, aparte de ser apoyados por la ley, son fortalecidos y fomentados por el cultivo de emociones de compasión y amor hacia todas las personas que tienen igual derecho a habitar este mundo sin sufrimientos evitables por el Estado. La retórica de Martin Luther King, en el contexto del movimiento de los derechos civiles en Estados Unidos, es un ejemplo de apelación a las emociones como fundamento y motor de realización de los valores políticos; también el papel jugado por el blues y los gospel en el movimiento de la equidad racial es un buen ejemplo de cómo apelar a las emociones tiene un papel fundamental en la integración de una sociedad bajo valores de igualdad y libertad en la promoción y consecución de su estabilidad. Metafóricamente, las emociones son el combustible que aviva nuestro deseo de ser justos, de ser inclusivos o de acabar con la marginación de los sectores social y económicamente más desfavorecidos (Lariguet, 2015; Nussbaum, 2011). Por su parte, las emociones de asco y odio hacia el que piensa diferente o la repugnancia hacia grupos minoritarios son el paradigma de la dimensión afectiva que no se debe promover o cultivar en una democracia: son emociones antiliberales que profundizan las divisiones sociales y globalizan la exclusión de miles de seres humanos.

De la unión entre compasión y deseo de justicia política surge lo que Nussbaum denomina la noción de "ciudadanía compasiva" (2014). Ciudadanía, en este contexto, implica una actitud de vida proactiva que busca mejorar las condiciones de vida propias y de la colectividad. Esta postura significa algo más 
que votar; encierra también el desarrollo de la conciencia de que un ciudadano es un ser que hace parte de un todo y de que el beneficio a la colectividad siempre repercute en el individuo. La ciudadanía compasiva estaría conformada concretamente por hombres y mujeres que son movidos por su repertorio emocional a la preocupación por los demás seres humanos, especialmente hacia aquellos a los que, debido a la injusticia social y a condiciones de vida deplorables, son más vulnerables y más propensos a no poder florecer humanamente: "uno de los peores aspectos de la privación es que despoja a la gente de sus aspiraciones y del sentido de la dignidad" (Nussbaum, 1997, p. 81).

La compasión, por consiguiente, como virtud característica de la nueva ciudadanía, puede estar acompañada de otras emociones pertinentes, como la indignación por el maltrato a los débiles y la desaprobación de situaciones de exclusión, desigualdad o negligencia por parte de las instituciones públicas que deberían hacerse cargo de aquellas circunstancias en donde se percibe el hundimiento de personas en lo infrahumano.

La inclusión de las personas con discapacidad física y mental en las políticas públicas, por ejemplo, ocupa un lugar importante dentro de esta comprensión de la benevolencia que, más allá de la caridad, propone nuevas lecturas de la justicia social para corregir las deficiencias de un contractualismo clásico regido por principios netamente económicos (Nussbaum, 2007). Por tanto, la compasión debe mover a los ciudadanos a exigir a los gobiernos, instituciones y entidades con capacidad de decisión que actúen en favor de aquellas personas que, como náufragos, se ahogan en sus necesidades apremiantes. La ciudadanía compasiva también nos debe llevar a enfocarnos en el trance de personas que son socialmente desiguales y, por esto mismo, en cierta medida impotentes para reaccionar ante situaciones de discriminación, hostilidad y otras formas de comportamiento que dan cuenta de los alcances de la crueldad humana (Pinedo, 2018).

Se trata, finalmente, de formar una racionalidad pública que se nutre del refinamiento de ciertas emociones políticas, como la compasión, que posibilitan una democracia renovada en donde se ataque el frecuente problema de la incapacidad para ver al prójimo como alguien plenamente humano. Esto implica, por tanto, incluir una perspectiva compasiva en el derecho, las leyes y las instituciones públicas, más allá de lo que se espera que todo gobierno haga mínimamente por suplir las necesidades básicas de todos los ciudadanos (Nussbaum, 2014). 
EN LAS ÚlTimAS DÉCADAS han surgido reflexiones éticas que, aunque no niegan la importancia de la razón, reivindican el papel esencial que juegan los sentimientos y las emociones en la moralidad y su valor en los comportamientos éticos. Esto ha llevado al planteamiento de una ética más contextualizada que pueda dar cuenta de la condición moral de los sujetos en las situaciones específicas de la vida cotidiana. Estas emociones operan como motivos para la acción, en tanto son intencionales y toman como su objeto a otras personas a la luz de su bienestar y especialmente de su dolor, de tal forma que impulsan a asumir compromisos efectivos con los demás y a realizar actos benéficos frente al estado de fragilidad en que se encuentra otro ser humano.

En el trasfondo de esta recuperación del vínculo entre emociones y vida moral se encuentra la noción de vulnerabilidad como condición humana que posibilita la conexión interna con el bien de otra persona y con el dolor que obstaculiza su florecimiento. Nussbaum, en su proyecto filosófico, convierte esta idea en un aspecto relevante y decisivo para entender el funcionamiento de emociones altruistas como la compasión y la influencia que esta puede ejercer en la consolidación de ideales de justicia y solidaridad en las actuales sociedades democráticas.

La vulnerabilidad es una condición común que compartimos los seres humanos, inevitablemente sometidos a los avatares de la fortuna que en cualquier momento pueden poner a prueba nuestro deseo de alcanzar una vida digna y floreciente. Si las situaciones de la fortuna llegan a ser graves, cualquier individuo puede verse apartado seriamente de la vida buena. Por tanto, solo otro ser humano, sometido a la misma fragilidad existencial, puede responder emocionalmente a las demandas de aquel que se hunde en su precariedad, porque reconoce en ese otro su propia humanidad y, por lo mismo, su natural vulnerabilidad.

La reflexión filosófica sobre la fragilidad hunde sus raíces en la filosofía y la literatura antiguas, en donde los relatos trágicos nos mostraban a individuos sometidos a los acontecimientos incontrolados de la fortuna, luchando existencialmente por mantenerse en la virtud y eligiendo cursos de acción que muchas veces terminaban afectando sustancialmente su calidad de vida. Aristóteles supo captar en estas narraciones lo difícil que es deliberar y elegir en medio de circunstancias no esperadas, y Nussbaum retoma del Estagirita y de la imaginación 
literaria griega esta idea de vulnerabilidad para establecer un derrotero de investigación ética poco explorado en la filosofía contemporánea.

En forma real o hipotética, ese otro que sufre podría ser yo atravesando la misma adversidad, porque soy un ser humano igual de vulnerable y expuesto continuamente a los embates de la fortuna. $\mathrm{Al}$ responder con sentimientos de compasión al sufrimiento ajeno, yo puedo comprender que el hecho de ser una persona próspera, sana o poderosa no me excluye de las filas de la humanidad necesitada. En realidad, con cualquier cambio en las circunstancias, por las vicisitudes de la fortuna, yo mismo puedo estar en una situación similar a la que contemplo.

Es en este contexto en donde Nussbaum da cabida a la imaginación comprensiva como un tipo de reconocimiento o comunidad entre el yo y ese otro que está sufriendo. La imaginación empática, acerca de las posibilidades y los obstáculos que están presentes en la vida de otra persona, acorta la distancia que con frecuencia establecemos con los demás, con su fragilidad, con su dignidad como personas. Sin ese reconocimiento es probable que permanezcamos en la indiferencia al no valorar a la otra persona como parte del propio ámbito de preocupaciones y, por lo mismo, que se opaque la extensión del interés por los demás. Es cierto que en ocasiones resulta difícil reconocer el dolor del otro, pero, como bien dice Nussbaum, el ejercicio de las ficciones imaginativas ayuda mucho a pensar qué se siente ser de otra raza que padece la discriminación, de otra orientación sexual que sufre la persecución de ciertos sectores de la sociedad, o pobre, migrante, enfermo y de una clase social sometida al abandono o la explotación.

Esto no significa, propiamente, que nos hagamos uno con el sufrimiento ajeno, pues la persona compasiva es consciente de la diferencia que hay entre su propia vida y la de aquel que se encuentra en grave dificultad: nos conmovemos por el dolor del otro y quedamos marcados por su situación, pero no sufrimos el mismo dolor del otro porque la suerte del que sufre es distinta de la de quien lo compadece. No obstante, lo importante de esta identificación imaginativa es que podemos llegar a ver a los extraños como compañeros de sufrimiento porque somos capaces de ensanchar, de hecho y en lo posible, los límites del "nosotros". Así, un sujeto deja de pensar en sí mismo para pensar en el otro, reconocerlo como diferente y valioso en sí mismo y, de esta manera, acercarse a él y acompañarle.

La de Nussbaum es, pues, una reflexión filosófica importante para el mundo actual, que nos permite contrastar los nobles ideales de búsqueda de una sociedad 
justa y solidaria con el sobrecogedor escenario de desvalorización de la vida, asco, degradación del otro, violencia y discriminación al cual asistimos en lo que va corriendo del siglo XXI. Su propuesta es una original reflexión que nos recuerda nuestra naturaleza benevolente, capaz de hacerse cargo de nuestra vulnerabilidad esencial y del sinnúmero de padecimientos a los cuales estamos expuestos en este mundo. Esa comprensión de la filosofía y de la vida es en sí misma una medicina para el alma, muy necesaria tanto para individuos como para la aspiración a una sociedad más justa.

\section{Referencias}

Abbate, F. (2017). La imaginación al poder según Nussbaum: terapia de las pasiones y autogobierno. En: G. Alessandrini (Ed.), El enfoque de las capacidades: ¿Una teoría pedagógica? (pp. 251-274). Quito: Abya Yala-Universidad Politécnica Salesiana.

Aristóteles (1985). Ética nicomaquea. Ética eudemia (J. Palli Bonet, trad.). Madrid: Gredos.

Arteta, A. (1996). La compasión, apología de una virtud bajo sospecha. Barcelona: Paidós.

Bieda, E. (2008). Aristóteles y la tragedia. Buenos Aires: Altamira.

Cabezas, M. (2014). Ética y emoción. El papel de las emociones en la construcción del juicio moral. Madrid: Plaza y Valdés.

Colmenarejo, R. (2017). El problema de la felicidad en Aristóteles: respuestas desde Francisco Suárez y Martha Nussbaum. Anales de la Cátedra Francisco Suárez, 51, 27-47.

Gil, M. (2014). La teoría de las emociones de Martha Nussbaum: el papel de las emociones en la vida pública (Tesis doctoral). Universidad de Valencia, Valencia, España.

Jiménez, D. (2016). Educación emocional para una ciudadania democrática. La propuesta de Martha Nussbaum. Quito: Centro de Publicaciones Pontificia Universidad Católica del Ecuador.

Knuuttila, (2004). Emotions in Ancient and Medieval Philosophy. Oxford: Clarendon Press. DOI: 10.1017/S0038713400005959

Kristjánsson, K. (2018). Virtuous Emotions. Oxford: Oxford University Press. 
Lacunza, M. (2015). La virtud aristotélica de la compasión a la base de la construcción de lazos sociales en el Estado. Discusiones en torno a la recepción del planteo antiguo por parte de Martha Craven Nussbaum. Ponencia presentada en las X Jornadas de Investigación en Filosofía, Facultad de $\mathrm{Hu}$ manidades y Ciencias de la Educación, Universidad Nacional de La Plata. Recuperado de: http://jornadasfilo.fahce.unlp.edu.ar/x-jornadas-2015/ comite-organizador/x-jornadas-2015/actas-x-jornadas-2015

Lariguet, G. (2015). Tres interpelaciones críticas a Political Emotions. Why Love Matters for Justice, de Martha Nussbaum. En: A. Fleck, E. Reich, \& J. M. Muniz (Eds.), Crise da democracia? / ¿Crisis de la democracia? (pp. 79-112). Florianópolis: Nefiponline.

MacIntyre, A. (1987). Tras la virtud. (Trad. A. Valcárcel). Barcelona: Crítica.

Máiz, R. (2010). La hazaña de la razón: la exclusión fundacional de las emociones en la teoría política moderna. Revista de Estudios Políticos, 149, 11-45.

Mélich, J. C. (2010). Ética de la compasión. Barcelona: Herder.

Modzelewski, H. (2017). Emociones, educación y democracia: una proyección de la teoría de las emociones de Martha Nussbaum. México: UNAM - Instituto de Investigaciones Filosóficas.

Nussbaum, M. (1995). La fragilidad del bien. Fortuna y ética en la tragedia y la filosofia griega. (Trad. A. Ballesteros). Madrid: Visor.

Nussbaum, M. (1996). Compassion: The Basic Social Emotion. Social Philosophy and Policy, 13(1), 27-58. DOI: 10.1017/s0265052500001515

Nussbaum, M. (1997). Justicia poética. La imaginación literaria y la vida pública. (Trad. C. Gardini). Barcelona: Andrés Bello.

Nussbaum, M. (2001). El cultivo de la humanidad. Una defensa clásica de la reforma en la educación liberal. Barcelona: Andrés Bello.

Nussbaum, M. (2002). Las mujeres y el desarrollo humano. El enfoque de las capacidades. Barcelona: Herder.

Nussbaum, M. (2003). La terapia del deseo. Teoria y práctica en la época helenistica. (Trad. M. Candel). Barcelona: Paidós.

Nussbaum, M. (2005). El conocimiento del amor. Ensayos sobre filosofía y literatura. (Trad. R. Orsi Portalo, \& J. M. Inarejos). Madrid: Antonio Machado.

Nussbaum, M. (2006). El ocultamiento de lo bumano. Repugnancia, verguenza y ley. (Trad. G. Zadunaisky). Buenos Aires: Katz. 
Nussbaum, M. (2007). Las fronteras de la justicia. Consideraciones sobre la exclusión. Barcelona: Paidós.

Nussbaum, M. (2008). Paisajes del pensamiento. La inteligencia de las emociones. (Trad. A. Maira) Barcelona: Paidós.

Nussbaum, M. (2011). Libertad de conciencia: el ataque a la igualdad de respeto. (Trad. P. Soley-Beltrán). Buenos Aires: Katz.

Nussbaum, M. (2012). Crear capacidades: propuesta para el desarrollo humano. Barcelona: Paidós.

Nussbaum, M. (2014). Emocionespoliticas. ¿Por qué el amor es importante para la justicia? (Trad. A. Santos Mosquera). Barcelona: Paidós.

Panea, J. (2018). El papel de las emociones en la esfera pública: la propuesta de M. C. Nussbaum. Recerca. Revista de Pensament i Análisi, 22, 111-131. DoI: 10.6035/Recerca.2018.22.7

Pettit, P. (1997). Republicanism: A Theory of Freedom and Government. Oxford: Oxford University Press.

Pinedo, I. (2018). De la benevolencia a la ciudadanía compasiva: La recuperación de conceptos claves para el cultivo de la democracia. Limite: Revista Interdisciplinaria de Filosofía y Psicologia, 13(41), 29-45.

Pinedo, I., \& Yáñez, J. (2017a). Las emociones y la vida moral: una lectura desde la teoría cognitivo-evaluadora de Martha Nussbaum. Veritas, 36, 47-72. DoI: $10.4067 /$ S0718-92732017000100003

Pinedo, I., \& Yáñez, J. (2017b). La dimensión cognitiva de las emociones en la vida moral: los aportes de Martha Nussbaum al estado actual de la discusión. Cuestiones de Filosofía, 3(20), 105-127. DoI: 10.19053/01235095. v3.n20.2017.5919

Rawls, J. (1979). Teoria de la justicia. (Trad. M. D. González). México: Fondo de Cultura Económica.

Rawls, J. (1995). Liberalismo político. (Trad. S. R. Madero Báez). México: Fondo de Cultura Económica.

Sandel, M. (2000). El liberalismo y los límites de la justicia. (Trad. M. L. Melón). Barcelona: Gedisa.

Seppala, E., Simon-Thomas, E., Brown, S., \& Worline, M. (Eds.). (2017). The Oxford Handbook of Compassion Science. New York: Oxford University Press. DOI: 10.1093/oxfordhb/9780190464684.001.0001

Tagore, R. (1963). La religión del hombre. (Trad. R. Cansinos-Assens). Madrid: Aguilar. 